University of Nebraska - Lincoln

DigitalCommons@University of Nebraska - Lincoln

2012

\title{
Electron attachment to molecules in a cluster environment
}

Ilya I. Fabrikant

University of Nebraska-Lincoln, ifabrikant@unl.edu

S. Caprasecca

The Open University, s.caprasecca@open.ac.uk

Gordon A. Gallup

University of Nebraska - Lincoln, ggallup1@unl.edu

J. D. Gorfinkiel

The Open University, J.Gorfinkiel@open.ac.uk

Follow this and additional works at: https://digitalcommons.unl.edu/physicsgallup

Part of the Physics Commons

Fabrikant, Ilya I.; Caprasecca, S.; Gallup, Gordon A.; and Gorfinkiel, J. D., "Electron attachment to molecules in a cluster environment" (2012). Gordon Gallup Publications. 55.

https://digitalcommons.unl.edu/physicsgallup/55

This Article is brought to you for free and open access by the Research Papers in Physics and Astronomy at DigitalCommons@University of Nebraska - Lincoln. It has been accepted for inclusion in Gordon Gallup Publications by an authorized administrator of DigitalCommons@University of Nebraska - Lincoln. 


\title{
Electron attachment to molecules in a cluster environment
}

\author{
I. I. Fabrikant, ${ }^{1,2, a)}$ S. Caprasecca, ${ }^{1, b)}$ G. A. Gallup, ${ }^{2}$ and J. D. Gorfinkiel ${ }^{1}$ \\ ${ }^{1}$ Department of Physical Sciences, The Open University, Walton Hall, \\ Milton Keynes MK7 6AA, United Kingdom \\ ${ }^{2}$ Department of Physics and Astronomy, University of Nebraska, Lincoln, Nebraska 68588, USA
}

(Received 25 February 2012; accepted 6 April 2012; published online 8 May 2012)

\begin{abstract}
Low-energy dissociative electron attachment (DEA) to the $\mathrm{CF}_{2} \mathrm{Cl}_{2}$ and $\mathrm{CF}_{3} \mathrm{Cl}$ molecules in a water cluster environment is investigated theoretically. Calculations are performed for the water trimer and water hexamer. It is shown that the DEA cross section is strongly enhanced when the attaching molecule is embedded in a water cluster, and that this cross section grows as the number of water molecules in the cluster increases. This growth is explained by a trapping effect that is due to multiple scattering by water molecules while the electron is trapped in the cluster environment. The trapping increases the resonance lifetime and the negative ion survival probability. This confirms qualitatively existing experiments on electron attachment to the $\mathrm{CF}_{2} \mathrm{Cl}_{2}$ molecule placed on the surface of $\mathrm{H}_{2} \mathrm{O}$ ice. The DEA cross sections are shown to be very sensitive to the position of the attaching molecule within the cluster and the orientation of the electron beam relative to the cluster. (C) 2012 American Institute of Physics. [http://dx.doi.org/10.1063/1.4706604]
\end{abstract}

\section{INTRODUCTION}

In many systems, electron-molecule collision processes occur in complex collision conditions whereby the effects of environments such as surfaces, bulk matter or clusterization are significant. ${ }^{1-4}$ These effects are particularly important in radiation chemistry and biology, ${ }^{5,6}$ beam-and photon-induced surface chemistry, ${ }^{7-9}$ atmospheric science, ${ }^{10,11}$ and environmental remediation. ${ }^{12}$

At energies of a few $\mathrm{eV}$ and below, vibrational excitation and dissociative electron attachment (DEA) are the most important processes through which electrons deposit energy and induce chemical transformations. In biological systems, it is important to know how these fundamental mechanisms are affected and modified in the presence of vital cellular components, in particular water. ${ }^{13}$ Numerical simulations ${ }^{14}$ indicate that the excess electron in solvated DNA bases, although initially delocalized, localizes around the nucleobases within a 15 fs time scale.

In the experiments of $\mathrm{Lu}$ and Sanche, it was shown that due to its strong trapping properties, $\mathrm{H}_{2} \mathrm{O}$ ice strongly enhances DEA processes in halocarbons ${ }^{15}$ and hydrogen halides. ${ }^{16}$ The DEA of electron trapped in ice to chlorofluorocarbons plays an important role in the ozone-depletion chemistry in polar stratospheric clouds. ${ }^{11,17}$

For the calculations of DEA cross sections in a cluster environment, the electron capture amplitude should be modified in order to incorporate multiple collision events in the cluster. Caron and Sanche ${ }^{18}$ used the multiple scattering approach to obtain a scattering matrix incorporating such multiple collision events. This approach was used in Refs. 19 and 20 to calculate elastic electron scattering by water dimers and trimers. In the present work, we use the same formalism

\footnotetext{
a) E-mail: ifabrikant1@unl.edu.

b) Present address: Dipartimento di Chimica e Chimica Industriale, Università di Pisa, Via Risorgimento 35,56126 Pisa, Italy.
}

to find the attachment amplitudes and calculate DEA cross sections for two halocarbon molecules, $\mathrm{CF}_{2} \mathrm{Cl}_{2}$ and $\mathrm{CF}_{3} \mathrm{Cl}$, embedded in water clusters. DEA for both molecules was studied in the gas phase ${ }^{21-23}$ and the developed theoretical models are consistent with experimental observations. Both molecules attach electrons at low energies due to electron capture into the lowest unoccupied molecular orbital (LUMO) of the $a_{1}$ symmetry. In the $\mathrm{CF}_{3} \mathrm{Cl}$ molecule capture occurs at a relatively large energy, $1.83 \mathrm{eV}$, and the decay width of the corresponding intermediate negative ion is relatively small. In contrast, for $\mathrm{CF}_{2} \mathrm{Cl}_{2}$ the resonance occurs at a significantly lower energy, $0.98 \mathrm{eV}$, and is much wider. Accordingly, the DEA cross section peaks at a much lower energy and exhibits an additional zero-energy peak at room temperature due to contributions from excited vibrational states. $^{23}$

In the present paper, we use these results to modify electron attachment amplitudes in the presence of water clusters. We are looking at general trends treating the $\mathrm{CF}_{2} \mathrm{Cl}_{2}$ and $\mathrm{CF}_{3} \mathrm{Cl}$ molecules in the presence of the water trimers and hexamers. Although there are no experimental data for these systems, our results confirm the experimental observation ${ }^{15}$ of a strong enhancement of DEA due to electron trapping in the presence of water.

\section{FORMALISM}

We adopt for the whole system a coordinate system attached to the dissociating molecule. Typically, it would be the reference frame with the $\mathrm{z}$ axis along the molecular symmetry axis. The direction of the incident electron beam is given by the momentum vector $\mathbf{k}$.

Following Caron and Sanche, ${ }^{18}$ we start with the attachment amplitude (our definition of the partial attachment amplitude differs from that of Caron and Sanche by the factor 
$\sqrt{4 \pi}$ for an isolated molecule)

$$
V_{\mathbf{k}}(q)=\sum_{L} V_{L}(q) Y_{L}^{*}(\hat{k}),
$$

and the corresponding attachment amplitude in a cluster environment

$$
V_{\mathbf{k}}^{(c)}(q)=\sum_{L} B_{\mathbf{k} L} V_{L}(q) e^{i \mathbf{k} \cdot \mathbf{R}_{n}} .
$$

Here, $L=(l, m), V_{L}(q)$ is a partial attachment amplitude for the isolated molecule as a function of internal molecular coordinates $q$, and $\mathbf{R}_{n}$ are center-of-mass positions of subunits in the cluster. The coefficients $B_{\mathbf{k} L}$ are obtained from the linear equations

$$
\begin{aligned}
B_{\mathbf{k} L}= & \frac{1}{2} \sum_{n} \sum_{L_{1} L_{2} L_{2}^{\prime}} i^{l_{1}+l_{2}-l_{2}^{\prime}} B_{\mathbf{k} L_{2}} T_{L_{2} L_{2}^{\prime}}^{(n)}(-1)^{m_{2}^{\prime}} \\
& \times e^{-i \mathbf{k} \cdot \mathbf{R}_{n}} F_{m_{1} m-m_{2}^{\prime}}^{l_{1} l l_{2}^{\prime}} Y_{L_{1}}\left(\hat{R}_{n}\right) h_{l_{1}}^{+}\left(k R_{n}\right)+Y_{L}^{*}(\hat{k}),
\end{aligned}
$$

where $T_{L L^{\prime}}^{(n)}$ is the scattering T matrix for the $n$th subunit, $h_{l}^{+}(x)$ is the spherical Hankel function, and the coefficients $F_{m_{1} m_{2} m_{3}}^{l_{1} l_{2} l_{3}}$ are given by the equation

$$
\begin{aligned}
F_{m_{1} m_{2} m_{3}}^{l_{1} l_{2} l_{3}}= & {\left[4 \pi\left(2 l_{1}+1\right)\left(2 l_{2}+1\right)\left(2 l_{3}+1\right)\right]^{1 / 2} } \\
& \times\left(\begin{array}{ccc}
l_{1} & l_{2} & l_{3} \\
0 & 0 & 0
\end{array}\right)\left(\begin{array}{ccc}
l_{1} & l_{2} & l_{3} \\
m_{1} & m_{2} & m_{3}
\end{array}\right) .
\end{aligned}
$$

The $\left(\begin{array}{lll}\cdot & \cdot & . \\ \cdot & . & .\end{array}\right)$ s represent Wigner $3-j$ symbols.

The capture amplitude $V_{\mathbf{k}}^{(c)}(q)$ allows us to calculate the resonance width. Assuming that the electron wave function in the continuum is energy-normalized, we have

$$
\Gamma(q)=2 \pi \int\left|V_{\mathbf{k}}^{(c)}(q)\right|^{2} d \hat{k}
$$

For the calculation of the dissociative attachment cross section, we solve an inhomogeneous Schrödinger equation with a nonlocal complex potential ${ }^{24}$ which is constructed from the width function $\Gamma(q)$ and the shift function

$$
\Delta(E, q)=\frac{1}{2 \pi} \mathrm{P} \int_{0}^{\infty} d E^{\prime} \frac{\Gamma\left(E^{\prime}, q\right)}{E-E^{\prime}} .
$$

The basic equation of the nonlocal complex potential theory is solved by the quasiclassical method as described in Refs. 25 and 26. So far this theory has been developed for a one-dimensional case only, that is, it assumes only one vibrational coordinate dominates the dissociation path. The examples that will be discussed in the present paper also assume the one-dimensional approximation.

The dependence of the cross section on the orientation of the system relative to the direction of the electron beam is given by

$$
\sigma(E, \hat{k})=b(E)\left|V_{\mathbf{k}}^{(c)}\left(q_{F C}\right)\right|^{2},
$$

where $q_{F C}$ is the Franck-Condon (transition) point for the electron capture. It is defined by equating momenta for nuclear motion in the neutral state and the negative-ion state. In the one-dimensional case, adopted in the present paper, its calculation is straightforward. The quantity $b(E)$ is related to the DEA cross section averaged over orientations, $\bar{\sigma}(E)$,

$$
b(E)=8 \pi^{2} \frac{\bar{\sigma}(E)}{\Gamma(E)} .
$$

\section{SCATTERING CALCULATIONS}

The $\mathrm{T}$ matrix for electron scattering by the water molecule is calculated $a b$ initio, taking advantage of the fact that water belongs to the $\mathrm{C}_{2 v}$ point group. We obtain four blocks of space-spin symmetry ${ }^{2} A_{1},{ }^{2} B_{1},{ }^{2} A_{2}$, and ${ }^{2} B_{2}$ in the basis of real spherical harmonics. The details of the multi-channel R-matrix calculation performed can be found in Ref. 20. These matrices are then transformed into the complex spherical harmonics basis.

Since the internal geometry of the water molecules in the cluster is very similar to that of the isolated molecule, it is possible to perform a single calculation with the molecule oriented in a specific way and then perform a rotation in order to account for the orientation of the water molecules in the cluster. This allows us to minimize the computational resources required for the $a b$ initio step. The rotation is performed in the following way: first, for each water molecule we calculate the orientation of the $\mathrm{H}-\mathrm{O}-\mathrm{H}$ bonds in the reference frame of the attaching molecule (in the cluster). Then we determine the elements of the rotation matrix performing the transformation from the body frame of the $a b$ initio calculation to the frame of the attaching molecule. This transformation matrix allows us to find the corresponding Euler angles $\alpha, \beta, \gamma$ and perform a transformation of the scattering $\mathrm{T}$ matrix using the Wigner $D$ functions

$$
T_{l m l^{\prime} m^{\prime}}^{(n)}=\sum_{m_{1} m_{2}} D_{m m_{1}}^{l *}(\alpha, \beta, \gamma) D_{m^{\prime} m_{2}}^{l^{\prime}}(\alpha, \beta, \gamma) T_{l m_{1} l^{\prime} m_{2}}
$$

where $T_{l m l^{\prime} m^{\prime}}^{(n)}$ is the T-matrix element for molecule (sub-unit) $n$ in the frame of the attaching molecule.

Since each water molecule has a substantial dipole moment whose effect is screened by multiple scatterers, in multiple scattering theory for elastic collisions ${ }^{19,20}$ two types of $\mathrm{T}$ matrices were used: the first, the so-called trimmed matrix $T_{c}$, is calculated without dipole contribution for distances $r>a_{c}$ (we took $a_{c}$ to be the radius of the R-matrix sphere) and with an angular momentum cutoff such that contributions of all angular momenta higher than $l_{c}$ are ignored. The parameter $l_{c}$ is estimated as $k d$ where $d$ is a typical intermolecular distance. Parameter $l_{c}$ grows with energy, and the cross section exhibits discontinuities when $l_{c}$ increases by one unit. Therefore, a two-point interpolation procedure on the parameter $l$ between $l_{c}$ and $l_{c}+1$ was performed to obtain a smooth cross section in the discontinuity region. The same procedure is used in the present work.

The second matrix $T_{\text {dip }}$ was calculated without cutoffs. Inclusion of the effect of the dipole moment in the whole radial range is fundamental for obtaining a reasonable lowenergy elastic cross section. Since for the dissociative attachment process, in contrast to the elastic scattering, only lower angular momenta contribute to the capture amplitude, there is 
no need to calculate $T_{\text {dip }}$. However, the long-range interaction can contribute to the capture amplitude even for low values of $l$, an effect that is not completely taken into account in the current formulation.

Accordingly, this method of calculating the multiscattering effect in the capture amplitude has two sources of errors. The first is due to the interpolation procedure described above. Since we are doing DEA calculations in the low-energy region between 0 and $2 \mathrm{eV}$ and the process is dominated by low partial waves, this procedure leads to very small uncertainty in the DEA cross section. The second source of error is due to the neglect of the long-range dipolar and polarization interaction in the calculation of the attachment amplitude. This approximation does not allow formation of weakly bound states due to the long-range interaction that might lead to formation of vibrational Feshbach resonances. ${ }^{27-29}$ However, these states are very delocalized and extend beyond the cluster region. They usually lead to the process of intermolecular vibrational energy redistribution and formation of the parent negative ion (nondissociative attachment). In the present work, we are interested in states corresponding to electron trapping within the cluster that are important for bond breaking in the attaching molecule.

The more important effect is the dipolar and polarization interactions between the captured electron and the water molecules that we include in the calculation of the potential anion curve. This interaction changes the value of the vertical attachment energy (VAE), i.e., the energy of the anion state at the equilibrium position of the neutral. The polarization interaction, being negative, reduces the vertical attachment energy. However, depending on the configuration of molecular units in the water cluster, the dipolar interaction can give both positive or negative contribution. Because of more or less random orientation of water molecules in the cluster, the VAE shift due to the dipolar interaction is typically small, therefore the negative polarization shift dominates. This effect was observed in small methyl iodide clusters ${ }^{30}$ and mediumsize $\mathrm{CO}_{2}$ and $\mathrm{N}_{2} \mathrm{O}$ clusters. ${ }^{27,28}$ This change in VAE depends very weakly on the molecular geometry, therefore we adopt the approach used before in the treatment of attachment to physisorbed molecules ${ }^{31,32}$ and molecular clusters, ${ }^{30}$ and change VAE by a uniform shift $\Delta E_{\mathrm{VAE}}$ of the anion curve.

\section{STRUCTURE OF TRIMER AND HEXAMER WATER CLUSTERS WITH $\mathrm{CF}_{2} \mathrm{Cl}_{2}$ AND $\mathrm{CF}_{3} \mathrm{Cl}$}

All of the present geometry optimizations were carried out with GAMESS (Version 01/12/2009 (R3)) (Ref. 33) at the 6-31G(d) RHF-MP2 level. We have calculated geometries for $\mathrm{CF}_{2} \mathrm{Cl}_{2}\left(\mathrm{H}_{2} \mathrm{O}\right)_{3}, \mathrm{CF}_{2} \mathrm{Cl}_{2}\left(\mathrm{H}_{2} \mathrm{O}\right)_{6}, \mathrm{CF}_{3} \mathrm{Cl}\left(\mathrm{H}_{2} \mathrm{O}\right)_{3}$, and

TABLE I. Energies of formation of $\left(\mathrm{H}_{2} \mathrm{O}\right)_{3}$ and $\left(\mathrm{H}_{2} \mathrm{O}\right)_{6}$.

\begin{tabular}{lc}
\hline \hline & Energy (eV) \\
\hline $3 \mathrm{H}_{2} \mathrm{O} \rightarrow\left(\mathrm{H}_{2} \mathrm{O}\right)_{3}$ & -1.026 \\
$6 \mathrm{H}_{2} \mathrm{O} \rightarrow\left(\mathrm{H}_{2} \mathrm{O}\right)_{6}$ & -2.997 \\
$2\left(\mathrm{H}_{2} \mathrm{O}\right)_{3} \rightarrow\left(\mathrm{H}_{2} \mathrm{O}\right)_{6}$ & -0.945 \\
\hline \hline
\end{tabular}

TABLE II. Energies of formation of $\mathrm{CF}_{2} \mathrm{Cl}_{2}$ with $\mathrm{H}_{2} \mathrm{O},\left(\mathrm{H}_{2} \mathrm{O}\right)_{3}$, and $\left(\mathrm{H}_{2} \mathrm{O}\right)_{6}$.

\begin{tabular}{lr}
\hline \hline & Energy (eV) \\
\hline $3 \mathrm{H}_{2} \mathrm{O}+\mathrm{CF}_{2} \mathrm{Cl}_{2} \rightarrow \mathrm{CF}_{2} \mathrm{Cl}_{2}\left(\mathrm{H}_{2} \mathrm{O}\right)_{3}$ & -1.188 \\
$\left(\mathrm{H}_{2} \mathrm{O}\right)_{3}+\mathrm{CF}_{2} \mathrm{Cl}_{2} \rightarrow \mathrm{CF}_{2} \mathrm{Cl}_{2}\left(\mathrm{H}_{2} \mathrm{O}\right)_{3}$ & -0.162 \\
$6 \mathrm{H}_{2} \mathrm{O}+\mathrm{CF}_{2} \mathrm{Cl}_{2} \rightarrow \mathrm{CF}_{2} \mathrm{Cl}_{2}\left(\mathrm{H}_{2} \mathrm{O}\right)_{6}$ & -2.307 \\
$2\left(\mathrm{H}_{2} \mathrm{O}\right)_{3}+\mathrm{CF}_{2} \mathrm{Cl}_{2} \rightarrow \mathrm{CF}_{2} \mathrm{Cl}_{2}\left(\mathrm{H}_{2} \mathrm{O}\right)_{6}$ & -0.255 \\
$\left(\mathrm{H}_{2} \mathrm{O}\right)_{6}+\mathrm{CF}_{2} \mathrm{Cl}_{2} \rightarrow \mathrm{CF}_{2} \mathrm{Cl}_{2}\left(\mathrm{H}_{2} \mathrm{O}\right)_{6}$ & 0.697 \\
\hline \hline
\end{tabular}

$\mathrm{CF}_{3} \mathrm{Cl}\left(\mathrm{H}_{2} \mathrm{O}\right)_{6}$, as well as $\left(\mathrm{H}_{2} \mathrm{O}\right)_{3}$ and $\left(\mathrm{H}_{2} \mathrm{O}\right)_{6}$. In Table I, we give the stability energies for the water clusters alone determined from the current calculations.

Table II gives energies of formation of $\mathrm{CF}_{2} \mathrm{Cl}_{2}$ with clusters. Examining the various numbers in Tables I and II, it is seen that the energy of interaction between $\mathrm{CF}_{2} \mathrm{Cl}_{2}$ and the clusters is considerably weaker than the internal binding energies of the clusters of water alone.

Typical geometries are shown in the figures. Figure 1 shows the skeletal geometry of the trimer cluster as well as a space-filling diagram.

The geometry of $\mathrm{CF}_{2} \mathrm{Cl}_{2}\left(\mathrm{H}_{2} \mathrm{O}\right)_{6}$ is shown in Fig. 2. Clearly, the three weakest hydrogen bonds of the water hexamer have been broken by the presence of the $\mathrm{CF}_{2} \mathrm{Cl}_{2}$. In the case of the $\mathrm{CF}_{2} \mathrm{Cl}_{2}\left(\mathrm{H}_{2} \mathrm{O}\right)_{6}$ cluster, the farthest apart atoms are two $\mathrm{H}$ atoms at $12.01 \AA$ separation. The two farthest apart $\mathrm{O}$ atoms are at $10.23 \AA$.

Two different local minima were found for $\mathrm{CF}_{3} \mathrm{Cl}\left(\mathrm{H}_{2} \mathrm{O}\right)_{3}$, and Table III shows the energies of formation for this halocarbon. We label the two trimer clusters as A and B. The A cluster has the water trimer off the positive dipole end of the molecule, and the B cluster has the trimer off the other end. In both cases, the two parts of the cluster are approximately coaxial. Figure 3 shows the skeletal geometries and spacefilling diagrams of the two $\mathrm{CF}_{3} \mathrm{Cl}$ water trimers.

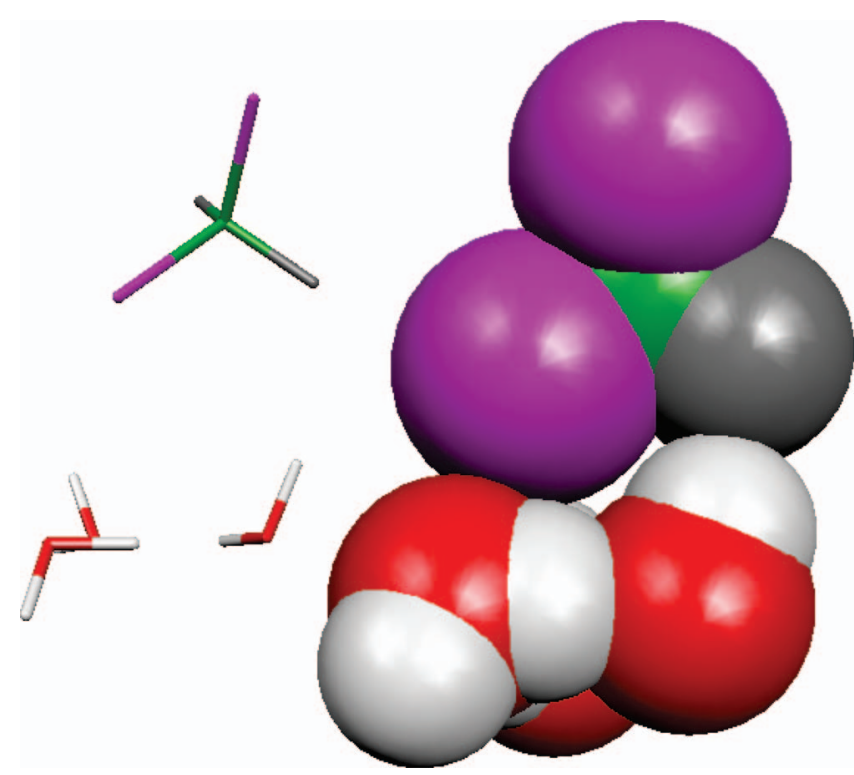

FIG. 1. Skeletal and space-filling views of the geometry of $\mathrm{CF}_{2} \mathrm{Cl}_{2}\left(\mathrm{H}_{2} \mathrm{O}\right)_{3}$. 


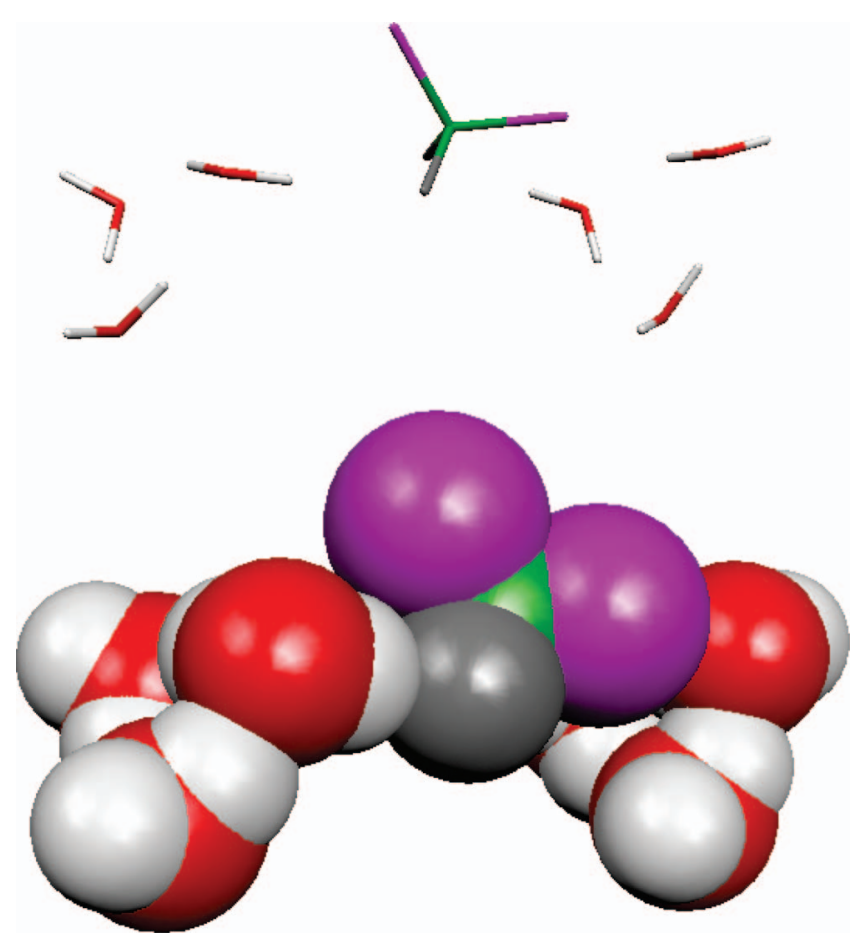

FIG. 2. Skeletal and space-filling views of the $\mathrm{CF}_{2} \mathrm{Cl}_{2}\left(\mathrm{H}_{2} \mathrm{O}\right)_{6}$ cluster.

The two hexamer clusters are rather different. The distance between the farthest apart $\mathrm{H}$ and $\mathrm{O}$ atoms is much smaller for the $\mathrm{CF}_{3} \mathrm{Cl}\left(\mathrm{H}_{2} \mathrm{O}\right)_{6}$ cluster: $7.62 \AA$ for the most distant $\mathrm{H}$-atom pair and $5.78 \AA$ for the most distant $\mathrm{O}$-atom pair. Figure 4 shows both structures for comparison.

Finally, in Fig. 5 we show the LUMO of the $\mathrm{CF}_{3} \mathrm{Cl}$ hexamer cluster. It is seen that the LUMO is strongly restricted to the central molecule.

Table IV presents VAE shifts due to the presence of water clusters for the calculated geometries. These were computed at the Hartree-Fock level with a correction using the MP2 method. An article ${ }^{34}$ by one of us describes the procedure. As a rule, the MP2 shifts are negative. However, in the case of the $\mathrm{CF}_{3} \mathrm{Cl}\left(\mathrm{H}_{2} \mathrm{O}\right)_{6}$ system, there is a relatively large positive contribution due to the electron interaction with water dipoles in the calculated geometry, and the net result is slightly positive.

TABLE III. Energies of formation of $\mathrm{CF}_{3} \mathrm{Cl}$ with $\mathrm{H}_{2} \mathrm{O},\left(\mathrm{H}_{2} \mathrm{O}\right)_{3}$, and $\left(\mathrm{H}_{2} \mathrm{O}\right)_{6}$. The two trimer clusters are labeled A and B.

\begin{tabular}{lr}
\hline \hline & Energy (eV) \\
\hline $3 \mathrm{H}_{2} \mathrm{O}+\mathrm{CF}_{3} \mathrm{Cl} \rightarrow \mathrm{CF}_{3} \mathrm{Cl}\left(\mathrm{H}_{2} \mathrm{O}\right)_{3} \mathrm{~A}$ & -1.149 \\
$\left(\mathrm{H}_{2} \mathrm{O}\right)_{3}+\mathrm{CF}_{3} \mathrm{Cl} \rightarrow \mathrm{CF}_{3} \mathrm{Cl}\left(\mathrm{H}_{2} \mathrm{O}\right)_{3} \mathrm{~A}$ & -0.123 \\
$3 \mathrm{H}_{2} \mathrm{O}+\mathrm{CF}_{3} \mathrm{Cl} \rightarrow \mathrm{CF}_{3} \mathrm{Cl}\left(\mathrm{H}_{2} \mathrm{O}\right)_{3} \mathrm{~B}$ & -1.191 \\
$\left(\mathrm{H}_{2} \mathrm{O}\right)_{3}+\mathrm{CF}_{3} \mathrm{Cl} \rightarrow \mathrm{CF}_{3} \mathrm{Cl}\left(\mathrm{H}_{2} \mathrm{O}\right)_{3} \mathrm{~B}$ & -0.165 \\
$6 \mathrm{H}_{2} \mathrm{O}+\mathrm{CF}_{3} \mathrm{Cl} \rightarrow \mathrm{CF}_{3} \mathrm{Cl}\left(\mathrm{H}_{2} \mathrm{O}\right)_{6}$ & -2.668 \\
$2\left(\mathrm{H}_{2} \mathrm{O}\right)_{3}+\mathrm{CF}_{3} \mathrm{Cl} \rightarrow \mathrm{CF}_{3} \mathrm{Cl}\left(\mathrm{H}_{2} \mathrm{O}\right)_{6}$ & -0.617 \\
$\left(\mathrm{H}_{2} \mathrm{O}\right)_{6}+\mathrm{CF}_{3} \mathrm{Cl} \rightarrow \mathrm{CF}_{3} \mathrm{Cl}\left(\mathrm{H}_{2} \mathrm{O}\right)_{6}$ & 0.328 \\
\hline \hline
\end{tabular}

(a)

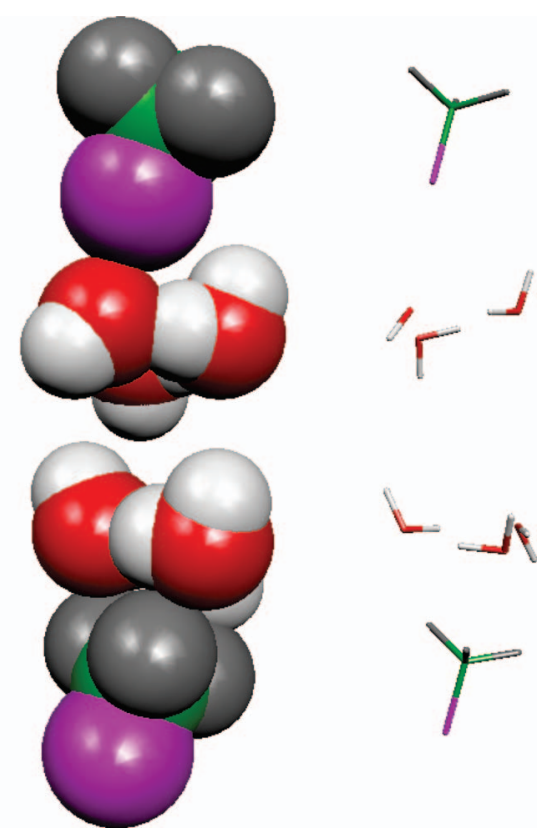

FIG. 3. Skeletal and space-filling views of geometries of two $\mathrm{CF}_{3} \mathrm{Cl}\left(\mathrm{H}_{2} \mathrm{O}\right)_{3}$ isomers.

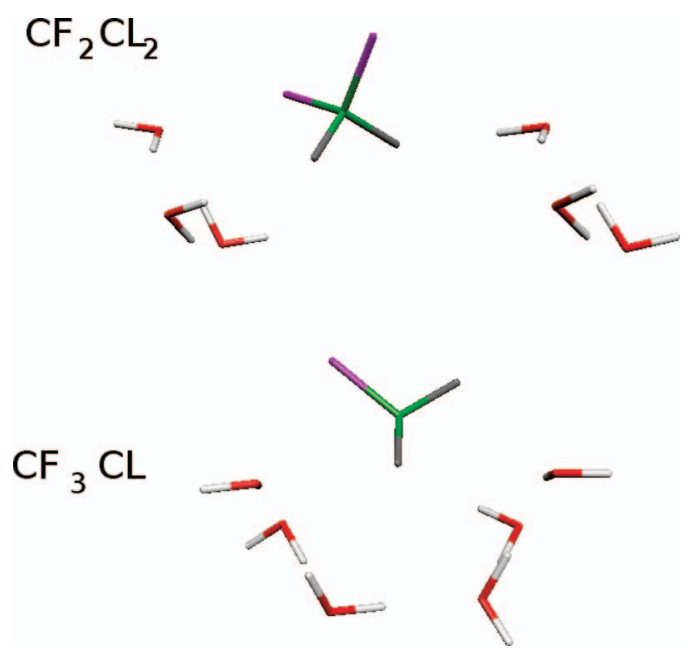

FIG. 4. A comparison of the geometries of the two hexamer clusters. It is seen that there is one more hydrogen bond in the $\mathrm{CF}_{3} \mathrm{Cl}$ case.
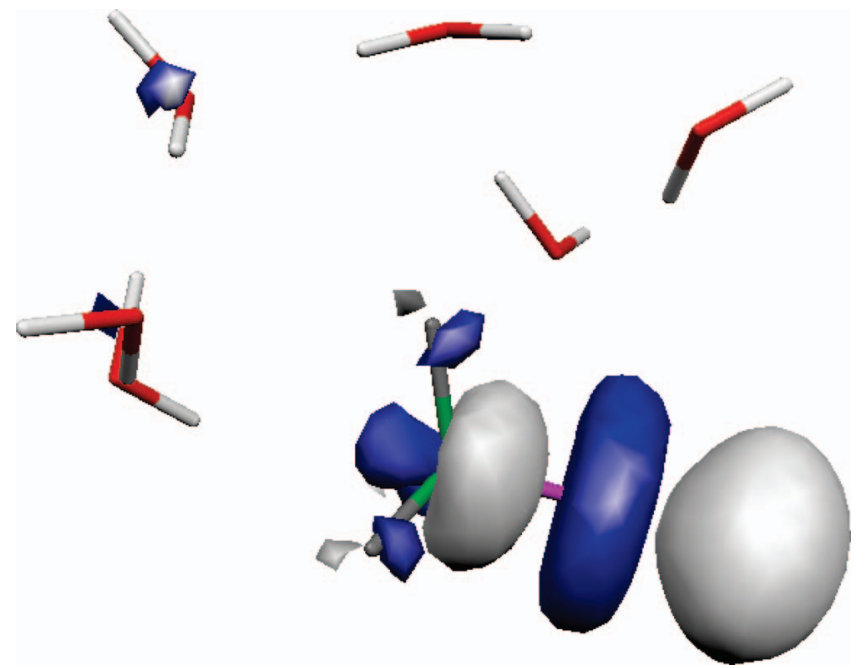

FIG. 5. The geometry and LUMO of $\mathrm{CF}_{3} \mathrm{Cl}\left(\mathrm{H}_{2} \mathrm{O}\right)_{6}$. 
TABLE IV. VAE shifts (in eV) due to the presence of the water cluster. Hartree-Fock values and MP2-level values are presented.

\begin{tabular}{lccccc}
\hline \hline & $\mathrm{CF}_{2} \mathrm{Cl}_{2}\left(\mathrm{H}_{2} \mathrm{O}\right)_{3}$ & $\mathrm{CF}_{2} \mathrm{Cl}_{2}\left(\mathrm{H}_{2} \mathrm{O}\right)_{6}$ & $\mathrm{CF}_{3} \mathrm{Cl}\left(\mathrm{H}_{2} \mathrm{O}\right)_{3}(\mathrm{~A})$ & $\mathrm{CF}_{3} \mathrm{Cl}\left(\mathrm{H}_{2} \mathrm{O}\right)_{3}(\mathrm{~B})$ & $\mathrm{CF}_{3} \mathrm{Cl}\left(\mathrm{H}_{2} \mathrm{O}\right)_{6}$ \\
\hline $\mathrm{HF}$ & -0.0571 & -0.1279 & 0.2721 & -0.0050 & 0.3157 \\
$\mathrm{MP} 2$ & -0.0601 & -0.2017 & -0.0576 & -0.1426 & 0.0169 \\
\hline \hline
\end{tabular}

\section{RESULTS AND DISCUSSION}

Figure 6 presents cross sections for DEA to the isolated $\mathrm{CF}_{2} \mathrm{Cl}_{2}$ molecule and the $\mathrm{CF}_{2} \mathrm{Cl}_{2}\left(\mathrm{H}_{2} \mathrm{O}\right)_{3}$ and $\mathrm{CF}_{2} \mathrm{Cl}_{2}\left(\mathrm{H}_{2} \mathrm{O}\right)_{6}$ systems. The results show a significant and systematic increase of the DEA cross section with the increase of the number of water molecules in the cluster. Moreover, for the $\mathrm{CF}_{2} \mathrm{Cl}_{2}\left(\mathrm{H}_{2} \mathrm{O}\right)_{6}$ system a significant enhancement is also observed at very low energies. Note that the results are presented only for the ground vibrational state, therefore the zero-energy peak is not due to higher-excited states which are present at increased vibrational temperature. ${ }^{23}$

To clarify the origin of this effect, in Fig. 7 we plot the resonance width as a function of electron energy for the equilibrium nuclear geometry. At low energies, the resonance width is significantly suppressed (by a factor 1.5 to 2 ) as compared to the width for the isolated molecule. The small value of the width leads to the higher negative ion survival probability and higher DEA cross section. In view of the oscillating behavior of the width as a function of the electron energy, this effect is apparently due to multiple scattering events. The interference at low energies is typically destructive for the width that represents electron capture into the cage formed by water molecules. We conclude that multiple scattering leads to electron trapping in the $\mathrm{CF}_{2} \mathrm{Cl}_{2}\left(\mathrm{H}_{2} \mathrm{O}\right)_{n}$ moiety and an increase in the negative ion lifetime.

These results confirm observations of Lu and Sanche ${ }^{15}$ of an order-of-magnitude enhancement of electron attachment to $\mathrm{CF}_{2} \mathrm{Cl}_{2}$ due to electron trapping on the ice surface with the formation of so-called precursor (rather than solvated) electron states. However, because of the small size of clusters in

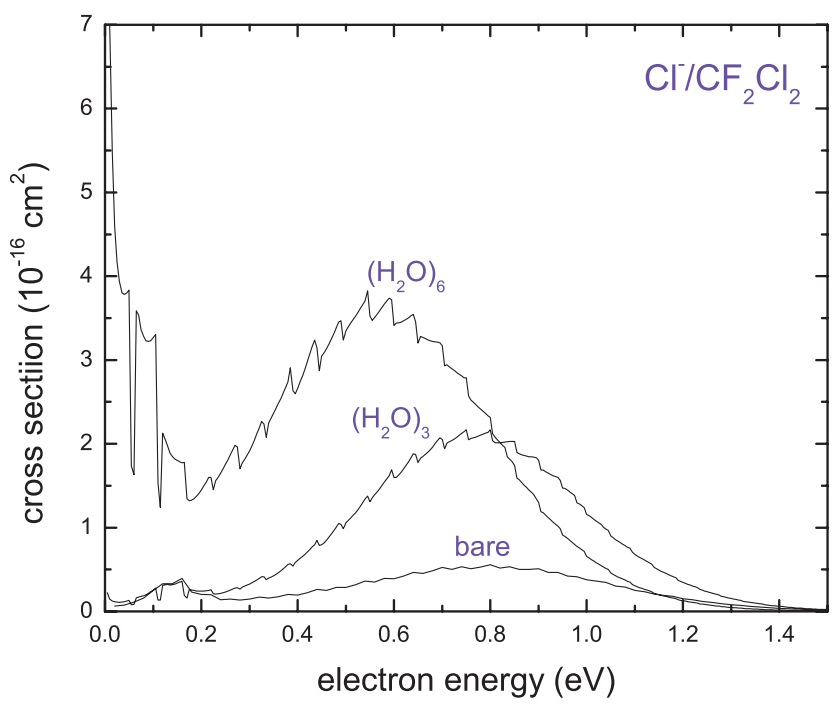

FIG. 6. DEA cross sections for $\mathrm{CF}_{2} \mathrm{Cl}_{2}$. Results are given for the isolated $\mathrm{CF}_{2} \mathrm{Cl}_{2}$, for $\mathrm{CF}_{2} \mathrm{Cl}_{2}\left(\mathrm{H}_{2} \mathrm{O}\right)_{3}$ and for $\mathrm{CF}_{2} \mathrm{Cl}_{2}\left(\mathrm{H}_{2} \mathrm{O}\right)_{6}$. the present calculations, this comparison is of more qualitative, rather than quantitative, character.

In Fig. 8, we present DEA cross sections for $\mathrm{CF}_{3} \mathrm{Cl}\left(\mathrm{H}_{2} \mathrm{O}\right)_{3}$ and $\mathrm{CF}_{3} \mathrm{Cl}\left(\mathrm{H}_{2} \mathrm{O}\right)_{6}$ systems. The effect is also significant here and reaches the order of magnitude when going from an isolated molecule to the $\mathrm{CF}_{3} \mathrm{Cl}\left(\mathrm{H}_{2} \mathrm{O}\right)_{6}$ system. As in the case of $\mathrm{CF}_{2} \mathrm{Cl}_{2}$, this is due to the suppression of the width at low electron energies shown in Fig. 9.

The cross section enhancement for the $\mathrm{B}$ isomer of $\mathrm{CF}_{3} \mathrm{Cl}\left(\mathrm{H}_{2} \mathrm{O}\right)_{3}$ is substantially stronger than for the $\mathrm{A}$ isomer. We should note here that the structure of the electron wave function is determined by the interference due to multiple scattering by water molecules, and this interference can affect the resonance width substantially even for apparently unfavorable geometries like geometry B in Fig. 3. In addition, for the isomer B the VAE shift is bigger in absolute magnitude (Table IV), mainly due to the polarization interaction between the intermediate negative ion and water molecules. However, the main part of the enhancement is due to the electron trapping. In particular, the net VAE shift for the $\mathrm{CF}_{3} \mathrm{Cl}\left(\mathrm{H}_{2} \mathrm{O}\right)_{6}$ system is slightly positive, see Table IV. Nevertheless, the enhancement is still very significant.

\section{MODEL CALCULATIONS OF THE POSITION DEPENDENCE AND ORIENTATIONAL DEPENDENCE}

In this section, we analyze two effects: the dependence of the cross section on the position of the attaching molecule relative to the cluster and the dependence of the cross section on the orientation of the electron beam relative to the cluster.

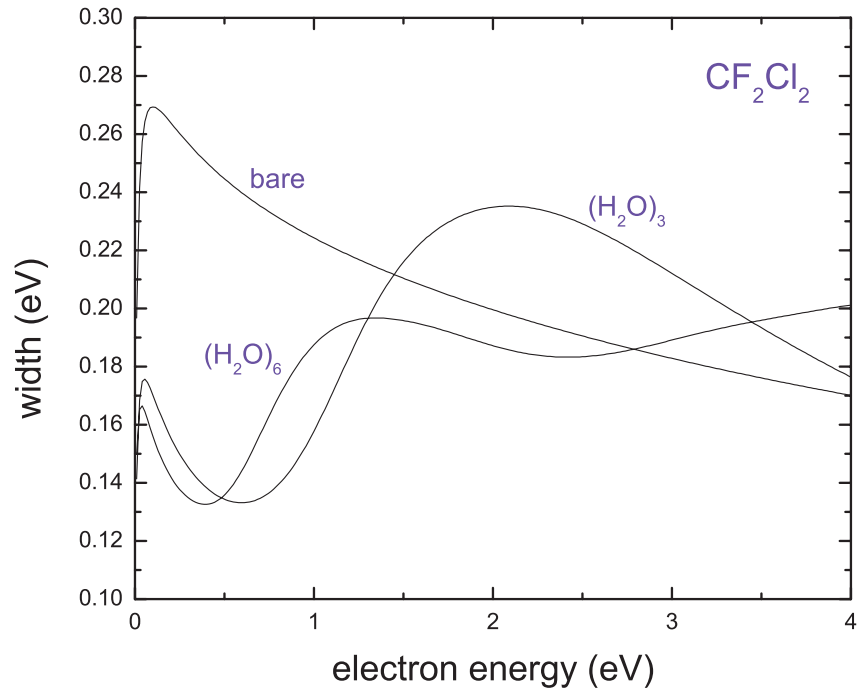

FIG. 7. The resonance width as a function of energy for the equilibrium internuclear geometry. Results are given for the isolated $\mathrm{CF}_{2} \mathrm{Cl}_{2}$, for $\mathrm{CF}_{2} \mathrm{Cl}_{2}\left(\mathrm{H}_{2} \mathrm{O}\right)_{3}$ and for $\mathrm{CF}_{2} \mathrm{Cl}_{2}\left(\mathrm{H}_{2} \mathrm{O}\right)_{6}$. 


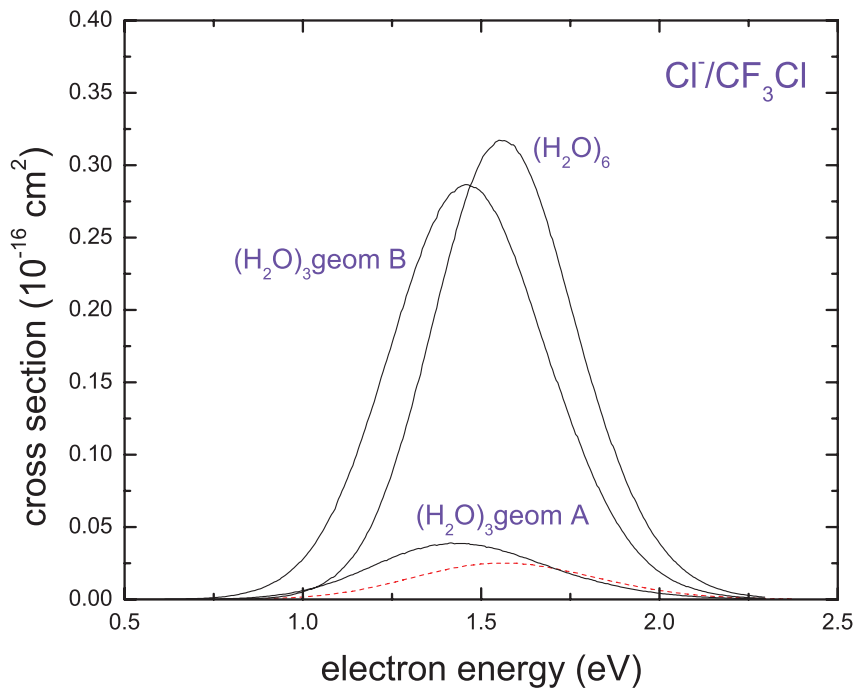

FIG. 8. DEA cross sections for $\mathrm{CF}_{3} \mathrm{Cl}$. Results are given for the isolated $\mathrm{CF}_{3} \mathrm{Cl}$ (red dashed line), for two isomers of $\mathrm{CF}_{3} \mathrm{Cl}\left(\mathrm{H}_{2} \mathrm{O}\right)_{3}$ and for $\mathrm{CF}_{3} \mathrm{Cl}\left(\mathrm{H}_{2} \mathrm{O}\right)_{6}$.

It is clear that when the molecule is positioned well outside the cluster, the DEA cross section should be close to that for the isolated molecule. As the molecule gets closer, the trapping effects start to play a role and vary drastically when the position of the molecule relative to the cluster changes. Therefore, it is of interest to analyze how the enhancement effect depends on the position of the attaching molecule in the cluster.

To investigate this dependence for the $\mathrm{CF}_{3} \mathrm{Cl}$ molecule, we adopted a model geometry of the hexamer water cluster whereby the oxygen atoms are placed in the vertices of a regular prism with bases formed by two equilateral triangles with side length $4 \AA$. The line joining the centers of the triangles (central line) was chosen to be perpendicular to them, and the distance between them was chosen to be $4 \AA$. The orientation of each water molecule in the reference frame formed by

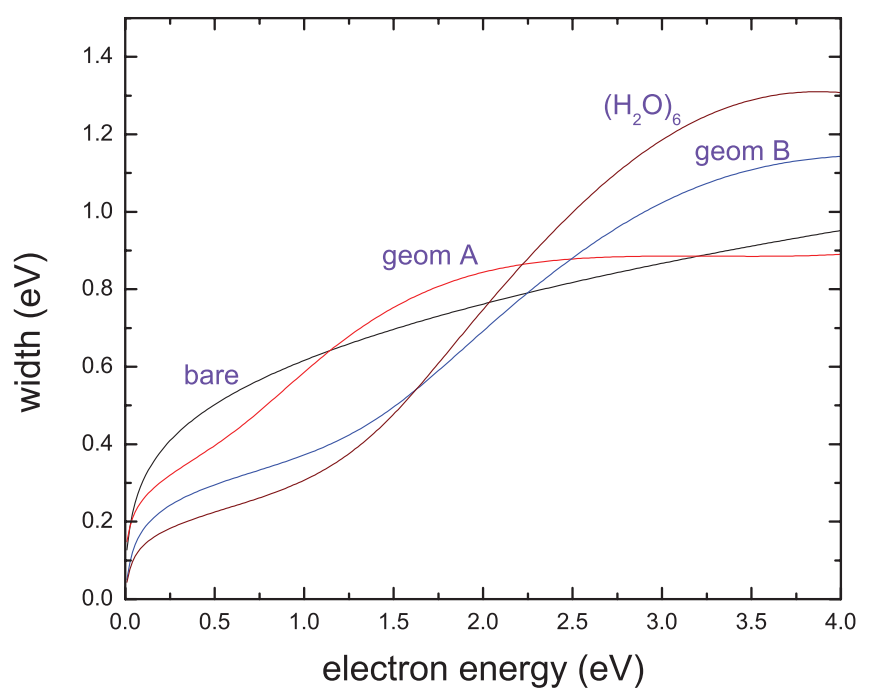

FIG. 9. The resonance width as a function of energy for the equilibrium internuclear geometry. Results are given for the isolated $\mathrm{CF}_{3} \mathrm{Cl}$, for two isomers of $\mathrm{CF}_{3} \mathrm{Cl}\left(\mathrm{H}_{2} \mathrm{O}\right)_{3}$ and for $\mathrm{CF}_{3} \mathrm{Cl}\left(\mathrm{H}_{2} \mathrm{O}\right)_{6}$.

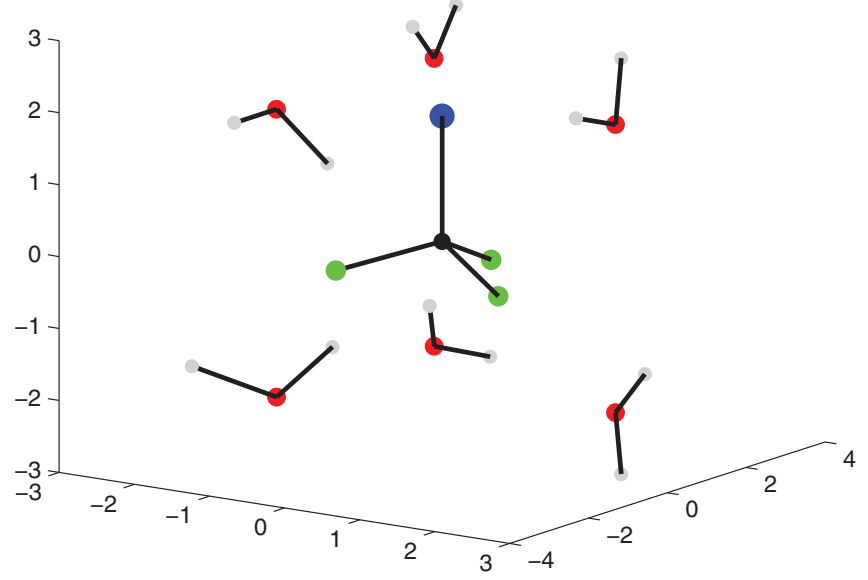

FIG. 10. The geometry of the model $\mathrm{CF}_{3} \mathrm{Cl}\left(\mathrm{H}_{2} \mathrm{O}\right)_{6}$ system with the $\mathrm{C}$ atom positioned at the center of the coordinate system discussed in text. The length units are in $\AA$.

the oxygen atoms was specified by three Euler angles $\left(\alpha_{n}, \beta_{n}\right.$, $\left.\gamma_{n}\right), n=1, \ldots, 6$ which were chosen randomly. Results do not change qualitatively when these angles vary, although quantitative difference might be substantial. The $\mathrm{CF}_{3} \mathrm{Cl}$ molecule was oriented along the central line, and the position of the $\mathrm{C}$ atom was varied. Figure 10 demonstrates the model geometry for some particular set of Euler angles.

In Fig. 11, we present the cross section as a function of the electron energy for different positions of $\mathrm{CF}_{3} \mathrm{Cl}$. The trapping effect is substantial and varies drastically when the molecule is positioned within the prism or close to the prism's surface. However, the enhancement decreases rapidly when the molecule is moved away from the cluster.

The cross sections presented so far are averaged over all cluster orientations. However, the calculated cross section strongly depends on orientation of the cluster relative to the incident electron beam. To illustrate this dependence,

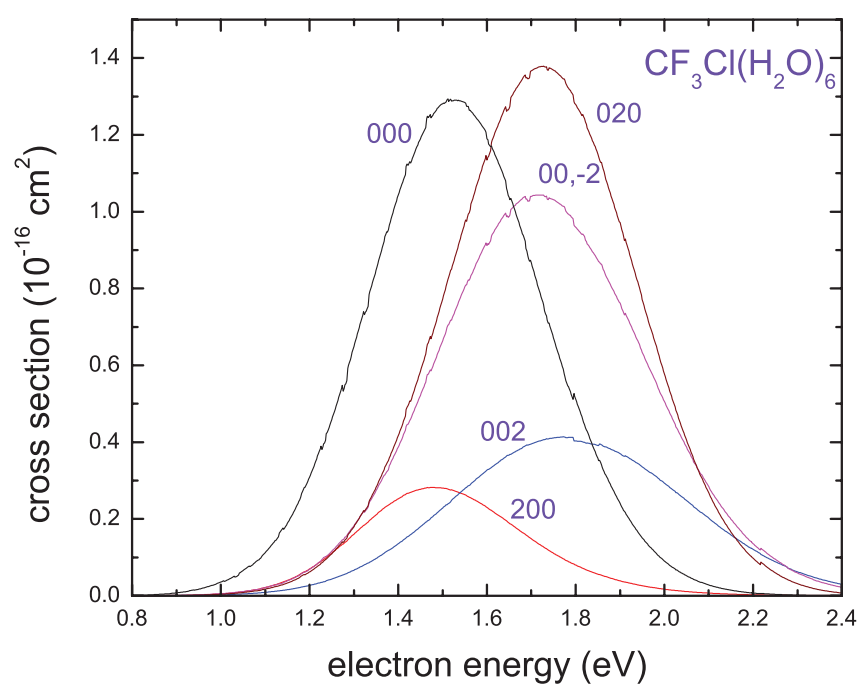

FIG. 11. DEA cross sections for the model $\mathrm{CF}_{3} \mathrm{Cl}\left(\mathrm{H}_{2} \mathrm{O}\right)_{6}$ system. Numbers near the curves indicate the Cartesian coordinates $x, y, z$ (in $\AA$ ) of the $\mathrm{C}$ atom in the coordinate system shown in Fig. 10. 


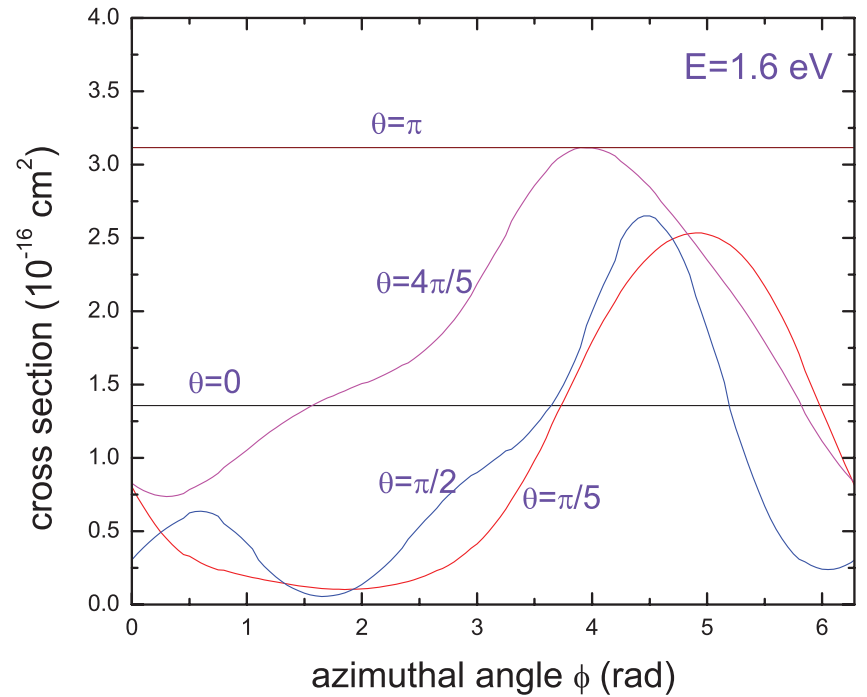

FIG. 12. DEA cross sections for the model $\mathrm{CF}_{3} \mathrm{Cl}\left(\mathrm{H}_{2} \mathrm{O}\right)_{6}$ system at $E=1.6 \mathrm{eV}$ for different orientations of the electron beam $(\theta, \phi)$ relative to the cluster. The $\mathrm{C}$ atoms are positioned at the center of the coordinate system shown in Fig. 10.

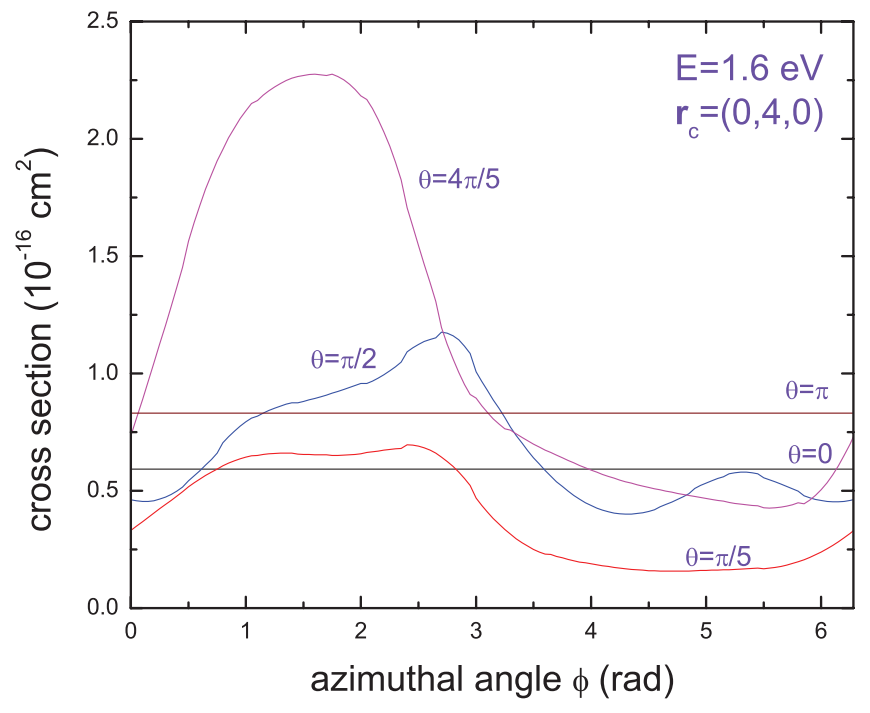

FIG. 13. The same as Fig. 12 for $\mathbf{r}_{c}=(0,4,0) \AA$.

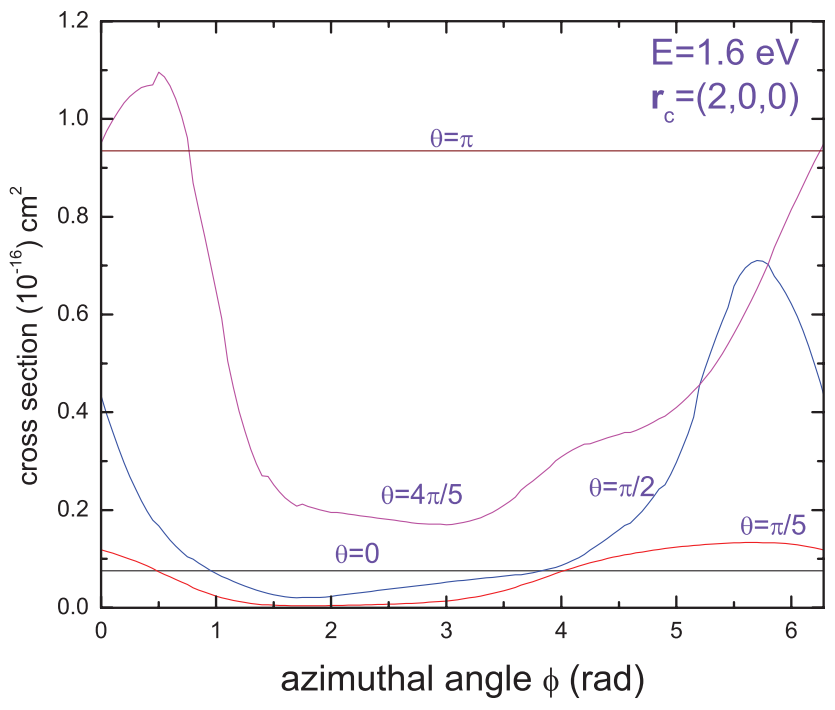

FIG. 14. The same as Fig. 12 for $\mathbf{r}_{c}=(2,0,0) \AA$.

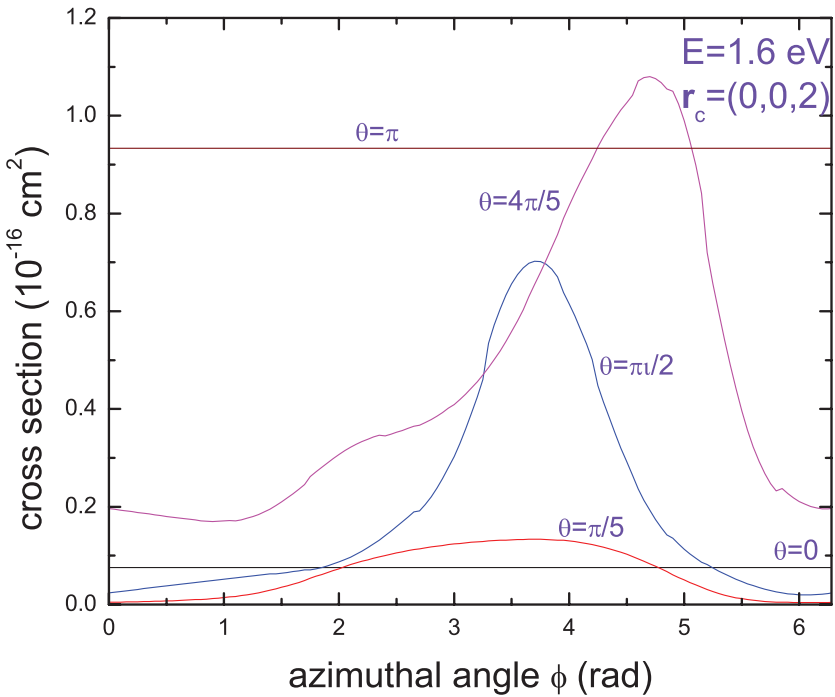

FIG. 15. The same as Fig. 12 for $\mathbf{r}_{c}=(0,0,2) \AA$.

we characterize the direction of the incident electron beam by the spherical angles $\theta, \phi$ in the coordinate system shown in Fig. 10. In Figs. 12-15, we present the cross section as a function of angles $\theta, \phi$ for different positions of the $\mathrm{CF}_{3} \mathrm{Cl}$ molecule. The trapping effect changes drastically with the angles. It is also important whether the molecule is placed in front or behind the cluster relative to the incident beam.

\section{CONCLUSION}

Using the multiple scattering theory, we have investigated DEA processes in resonant electron-molecule collisions in a water cluster environment. Calculations of the resonance width show that the resonance lifetime for electron captured in the LUMO is increased significantly when the molecule is embedded in a water cluster. This effect leads to a higher negative ion survival probability and a significant increase of the DEA cross sections. The trend seems to be quite general, although quantitative results are very sensitive to the geometry of the cluster, the position of the attaching molecule relative to the cluster, and the relative orientation of the cluster and the electron beam.

Although direct experiments for the systems described in the present paper are not available, the order of magnitude enhancement confirms observations of Lu and Sanche, ${ }^{15}$ who detected a strong increase in electron attachment to the $\mathrm{CF}_{2} \mathrm{Cl}_{2}$ molecule when it was placed on the surface of $\mathrm{H}_{2} \mathrm{O}$ ice. The appearance of the zero-energy peak in $\mathrm{CF}_{2} \mathrm{Cl}_{2}$ with increasing number of molecular units in the water cluster is also in agreement with observation.

Many questions remain to be addressed in this complicated problem. In particular, it would be interesting to see how vibrational Feshbach resonances, which strongly influence DEA processes in biological molecules, ${ }^{35,36}$ are affected by the cluster environment. Previous studies ${ }^{30,32}$ have shown that cluster and surface environments completely suppress a pronounced vibrational Feshbach resonance in the methyl iodide molecule. 


\section{ACKNOWLEDGMENTS}

This work was supported in part by the National Science Foundation under Grant No. PHY-0969381, and by a Marie Curie International Incoming Fellowship (FP7PEOPLE-2009-IIF-252714).

${ }^{1}$ R. E. Palmer and P. J. Rous, Rev. Mod. Phys. 64, 383 (1992).

${ }^{2}$ L. Sanche, A. D. Bass, P. Ayotte, and I. I. Fabrikant, Phys. Rev. Lett. 75, 3568 (1995).

${ }^{3}$ D. C. Marinica, D. Teillet-Billy, J.-P. Gauyacq, M. Michaud, and L. Sanche, Phys. Rev. B 64, 085408 (2001).

${ }^{4}$ D. C. Marinica, D. Teillet-Billy, and J. P. Gauyacq, Phys. Rev. B 71, 115438 (2005).

${ }^{5}$ L. Sanche, Radiat. Phys. Chem. 32, 269 (1988).

${ }^{6}$ L. Sanche, Eur. Phys. J. D 35, 367 (1995).

${ }^{7}$ R. D. Ramsier and J. T. Yates, Jr., Surf. Sci. Rep. 12, 247 (1991).

${ }^{8}$ T. D. Harris, D. H. Lee, M. Q. Blumberg, and C. R. Arumainayagam, J. Phys. Chem. 99, 9530 (1995).

${ }^{9}$ Laser Spectroscopy and Photochemistry on Metal Surfaces, edited by H. L. Dai and W. Ho (World Scientific, Singapore, 1995).

${ }^{10}$ Q.-B. Lu and Th. E. Madey, Phys. Rev. Lett. 82, 4122 (1999).

${ }^{11}$ Q.-B. Lu and L. Sanche, Phys. Rev. Lett. 87, 078501 (2001).

${ }^{12}$ P. D. Burrow, K. Aflatooni, and G. A. Gallup, Environ. Sci. Technol. 34, 3368 (2000).

${ }^{13}$ S. Ptasinka and L. Sanche, Phys. Rev. E 75, 031915 (2007).

${ }^{14}$ M. Smyth and J. Kohanoff, Phys. Rev. Lett. 106, 238108 (2011).

${ }^{15}$ Q.-B. Lu and L. Sanche, Phys. Rev. B 63, 153403 (2001).

${ }^{16}$ Q.-B. Lu and L. Sanche, J. Chem. Phys. 115, 5711 (2001).

${ }^{17}$ H. Tachikawa, Phys. Chem. Chem. Phys. 10, 2200 (2008).
${ }^{18}$ L. G. Caron and L. Sanche, Phys. Rev. Lett. 91, 113201 (2003).

${ }^{19}$ D. Bouchiha, L. G. Caron, J. D. Gorfinkiel, and L. Sanche, J. Phys. B 41, 045204 (2008)

${ }^{20}$ S. Caprasecca, J. D. Gorfinkiel, D. Bouchiha, and L. G. Caron, J. Phys. B 42, 095205 (2009).

${ }^{21}$ R. S. Wilde, G. A. Gallup, and I. I. Fabrikant, J. Phys. B 32, 663 (1999).

${ }^{22}$ M. Tarana, P. Wielgus, S. Roszak, and I. I. Fabrikant, Phys. Rev. A 79, 052712 (2009).

${ }^{23}$ K. Graupner, S. A. Haughey, T. A. Field, C. A. Mayhew, T. H. Hoffmann, O. May, J. Fedor, M. Allan, I. I. Fabrikant, E. Illenberger, M. Braun, M.-W. Ruf, and H. Hotop, J. Phys. Chem. A 114, 1474 (2010).

${ }^{24}$ W. Domcke, Phys. Rep. 208, 97 (1991).

${ }^{25}$ S. A. Kalin and A. K. Kazansky, J. Phys. B 23, 4377 (1990).

${ }^{26}$ G. A. Gallup, Y. Xu, and I. I. Fabrikant, Phys. Rev. A 57, 2596 (1998).

${ }^{27}$ J. M. Weber, E. Leber, M.-W. Ruf, and H. Hotop, Phys. Rev. Lett. 82, 516 (1999).

${ }^{28}$ E. Leber, S. Barsotti, I. I. Fabrikant, J. M. Weber, M.-W. Ruf, and H. Hotop, Eur. Phys. J. D 12, 125 (2000).

${ }^{29}$ I. I. Fabrikant and H. Hotop, Phys. Rev. Lett. 94, 063201 (2005).

${ }^{30}$ J. M. Weber, I. I. Fabrikant, E. Leber, M.-W. Ruf, and H. Hotop, Eur. Phys. J. D 11, 247 (2000).

${ }^{31}$ I. I. Fabrikant, Phys. Rev. A 76, 012902 (2007).

${ }^{32}$ I. I. Fabrikant, J. Phys. B 44, 225202 (2011).

${ }^{33}$ M. W. Schmidt, K. K. Baldridge, J. A. Boatz, S. T. Elbert, M. S. Gordon, J. H. Jensen, S. Koseki, N. Matsunaga, K. A. Nguyen, S. J. Su, T. L. Windus, M. Dupuis, and J. A. Montgomery, J. Comput. Chem. 14, 1347 (1993)

${ }^{34}$ G. A. Gallup, Phys. Rev. A 84, 012701 (2011).

${ }^{35}$ G. Hanel, B. Gstir, S. Denifl, P. Scheier, M. Probst, B. Farizon, M. Farizon, E. Illenberger, and T. D. Märk, Phys. Rev. Lett. 90, 188104 (2003).

${ }^{36}$ G. A. Gallup and I. I. Fabrikant, Phys. Rev. A 83, 012706 (2011). 